\title{
Life-span retrieval of public events: Reminiscence bump for high-impact events, recency for others
}

\author{
Ali İ. Tekcan ${ }^{1}$ - Aysecan Boduroglu ${ }^{1}$ - Aysu Mutlutürk ${ }^{1} \cdot$ Aslı Aktan Erciyes $^{1}$
}

Published online: 13 July 2017

(C) Psychonomic Society, Inc. 2017

\begin{abstract}
Although substantial evidence exists showing a reliable reminiscence bump for personal events, data regarding retrieval distributions for public events have been equivocal. The primary aim of the present study was to address life-span retrieval distributions of different types of public events in comparison to personal events, and to test whether the existing accounts of the bump can explain the distribution of public events. We asked a large national sample to report the most important, happiest, and saddest personal events and the most important, happiest, saddest, most proud, most fearful, and most shameful public events. We found a robust bump corresponding to the third decade of life for the happiest and the most important positive but not for the saddest and most important negative personal events. For the most important public events, a bump emerged only for the two most frequently mentioned events. Distributions of public events cued with emotions were marked by recency. These results point to potential differences in retrieval of important personal and public events. While the life-script framework well accounts for the findings regarding important personal events, a chronologically retroactive search seem to guide retrieval of public events. Reminiscence bump observed for the two public events suggest that age-at-event affects recall of public events to the degree that the events are high-impact ones that dominate nation's collective memory. Results provide further evidence
\end{abstract}

Ali İ. Tekcan

ali.tekcan@boun.edu.tr

1 Department of Psychology, Bogazici University, Bebek, 34342 İstanbul, Turkey that the bump is not unitary and points to importance of event type and memory elicitation method with regard to competing explanations of the phenomenon.

Keywords Reminiscence bump · Life-span retrieval . Autobiographical memory $\cdot$ Collective memory $\cdot$ Public events

Substantial work on life-span retrieval of autobiographical memories (ABMs) show that when adults remember their past, more memories come from the youth period (10-30 years of age) than would be expected on the basis of a typical forgetting function (Rubin, Wetzler, \& Nebes, 1986).This reminiscence bump has been one of the most robust findings in the memory literature (e.g., Conway \& Holmes, 2004; Fitzgerald, 1988; Rubin \& Schulkind, 1997). It emerges not only for personal memories but also for semantic information as well as people's preferences such as favorite books, music, or football players (Rubin, Rahhal, \& Poon, 1998; Janssen, Chessa, \& Murre, 2007; Janssen, Rubin, \& Conway, 2012; Sehulster, 1996). The bump has also been obtained across different age groups (Berntsen \& Rubin, 2002; Bohn, 2010; Fromholt \& Larsen, 1991; Fromholt et al., 2003; Jansari \& Parkin, 1996), elicitation methods (Fitzgerald, 1988; Koppel \& Berntsen, 2015a), and cultures (Conway, Wang, Hanyu, \& Haque, 2005; Janssen, Chessa, \& Murre, 2005; Tekcan \& Tartar, 2008).

Compared to memory for personal experiences, relatively little is known about retrieval of public events. Most of the existing empirical work on this issue attempted to identify the important events in a group's collective memory and changes over time or differences across groups (e.g., nations, ethnic 
groups; e.g., Schuman \& Corning, 2012; Zaromb, Butler, Agrawal, \& Roediger, 2014). Few others have focused on more specific events and themes in collective memory and the historical significance of such memories for different groups (Roediger \& DeSoto, 2014; Wertsch, 2017). Although a number of studies have also addressed life-span retrieval patterns of public events (e.g., Koppel, 2013; Schuman \& Corning, 2014; Schuman \& Scott, 1989), the data are nevertheless limited. The present study addresses life-span retrieval distribution for different types of public events in comparison to personal events with a focus on the reminiscence bump and attempts to evaluate the existing accounts of the bump.

\section{Life-span retrieval of important personal events}

A robust bump corresponding to youth emerges consistently for important personal (autobiographical) memories (e.g., Berntsen \& Rubin, 2002; Bohn, 2010; Fitzgerald, 1996; Holmes \& Conway, 1999; Rubin \& Schulkind, 1997; Rubin et al., 1986; Thomsen, Pillemer, \& Ivcevic, 2011). For instance, Holmes and Conway (1999) asked participants to report as many important personal memories as possible in 10 minutes, and found a bump peaking when the participants were ages 20 to 29 at the time of the retrieved memory. A bump corresponding to the same age period was obtained when adults reported the most important memories of their lives (Berntsen \& Rubin, 2002; Rubin \& Schulkind, 1997).

There have, however, been two important exceptions to the bump for important personal events. First, the location of the bump changes depending on the elicitation method. Koppel and Berntsen (2015a) showed in their review that the bump peaks about a decade earlier for word-cued memories (age 8.7 to 22.5) than for important memoires (age 15.1 to 27.9). Second, valence affects the bump for important personal memories. When negative personal important memories (e.g., saddest, most traumatic memory) are elicited, the bump disappears (Berntsen \& Rubin, 2002).

These consistent exceptions point to the strong possibility that what has been referred to as the "bump" may not be referring to the same memory phenomenon and may emerge as a result of different retrieval mechanisms. Therefore, identifying how the bump may or may not vary under different circumstances is essential to describing this phenomenon and for testing potential explanations (Janssen, 2015; Koppel \& Berntsen, 2015a). Indeed, this is well illustrated by the fact that the latter of the two exceptions noted above led to a novel theoretical account of the bump, the cultural life script (Berntsen \& Rubin, 2004; Rubin \& Berntsen, 2003).

\section{What accounts for the bump?}

There are a few alternative accounts of the bump for personal events. The cognitive account emphasizes the novelty and distinctiveness of the events that happen during youth. Accordingly, these events may require more effort after meaning and rehearsal, thus increasing the memorability of these experiences (Rubin et al., 1998). The biological account (e.g., Janssen, Murre, \& Meeter, 2008; Rubin et al., 1998) argues that the bump occurs because brain functions are at their peak during this period in an adult's life. The narrative/identity account is based on the idea that an adult identity starts to emerge in late adolescence and early adulthood (Conway, 2005; Erikson, 1950; Fitzgerald, 1988; Habermas \& Bluck; 2000; Conway \& Haque, 1999). In this period, people explore who they are, their personal, social, and political preferences, and their interactions with the world may be organized around those concerns. Therefore, experiences important for the self are more likely to be integrated to the narratives of the self and are more likely to be rehearsed and used as landmarks in later adulthood (Conway \& Holmes, 2004; Habermas \& Bluck, 2000; Rathbone, Moulin, \& Conway, 2008; Pillemer, 2001). This account also accommodates the possibility that experiences central to the self may also lead to additional bumps, even if these experiences occur later than late adolescence or early adulthood (e.g., Schrauf \& Rubin, 1998). The cultural life script account (Berntsen \& Rubin, 2002, 2004) suggests that life scripts-normative expectations about a typical lifeact as a framework in retrieval of autobiographical memories, especially the positive ones (e.g., Bernsten \& Rubin, 2002, 2004; Bohn, 2010; Erdoğan, Baran, Avlar, Tas, \& Tekcan, 2008; Ottsen \& Bernsten, 2014). Finally, life-story account integrates various aspects of especially the cognitive and life-script accounts, and adds that the bump for positive personal memories occur only for events that people have perceived control (Demiray, Gülgöz, \& Bluck, 2009; Glück \& Bluck, 2007).

Although there is empirical evidence supporting each of these predictions, the cultural life-script account is the most adequate account regarding life-span retrieval of important personal memories. It is able to explain the location of the bump as well as the dissociation between the retrieval distributions of positive and negative important memories (e.g., Berntsen \& Rubin, 2004; Koppel \& Berntsen, 2015a; Rubin \& Berntsen, 2003). 


\section{Life-span retrieval of important public events}

In a seminal study, Schuman and Scott (1989) asked a nationally representative sample of Americans "to list one or two most important public events that occurred within the last 50 years" (p. 363) and found that for some of the national or international public events/changes, people were more likely to mention an event that took place when they were in their late teens and early 20s. Rubin et al.'s (1998) reanalysis of Schuman and Scott's data confirmed a clear bump for World War II, the Vietnam War, and the JFK assassination. Koppel (2013), however, pointed out that only five of the 12 frequently listed events as most important in Schuman and Scott's study showed a bump corresponding to the youth period. Studies employing the same methodology in different nations led to similar results (e.g., Schuman, Akiyama, \& Knauper, 1998; Schuman \& Corning, 2012; Schuman, VinitzkySerousi, \& Vinokur, 2003); a bump emerged for some events but not others. For instance, in a comparison of Japanese and German collective memories, Schuman et al. (1998) found a bump corresponding to the third decade of life for WWII but no bump for the Holocaust (in Germany). In an excellent critical review of the literature on bump for public events, Koppel (2013) concluded that although the typical bump was the most common pattern (59\%), a substantial minority $(41 \%)$ of studies reported other retrieval distribution patterns (e.g., in $20 \%$ of the studies, individuals who were beyond childhood at the time of the event were equally likely to mention the event regardless of their birth cohort). Another criterion Koppel used to test the reliability of the bump was to test whether it was present in more than half of the studies and found that it was not. The inconsistency of the bump for public events is also illustrated by the fact that its location is more variable than that for personal events (e.g., Holmes \& Conway, 1999; Schuman et al, 1998; Schuman \& Corning, 2000; Schuman \& Corning, 2014). Thus, unlike for personal important memories, the life-span distribution for public events is rather variable, and factors contributing to this variability are not well understood.

\section{The present study}

The main aim of the present study was to provide comprehensive data regarding life-span retrieval of public versus personal events by using a large national sample. There are only a few studies comparatively addressing the bump for public and personal events across the life span (Holmes \& Conway; 1999; Howes \& Katz, 1992; Koppel \& Berntsen, 2016b). Two of these studies
(Howes \& Katz, 1992; Koppel \& Berntsen, 2016b) also involved comparison of cue types (word-cued vs. nonword-cued), which are not directly relevant to our study; we focus on their findings regarding important but not word-cued memories.

These three studies used different methodological approaches and yielded inconsistent data regarding whether there is a bump for public memories corresponding to a particular age period. In this regard, Howes and Katz (1992) is particularly hard to interpret because they provided participants atypical age ranges (e.g., 15-30; 31-45, etc.) from which events/memories should be retrieved. These time brackets make it impossible to discern whether a bump exists for the second or third decade of life. Holmes and Conway (1999) asked adults to report as many important personal and public events in 10 minutes. Results showed a bump for public events corresponding to the second decade of life and a bump for personal events corresponding to the third decade of life, in line with Erikson's developmental stages but also supporting, in a more general sense, the identity account of the bump. Most recently, Koppel and Berntsen (2016b) asked two separate age-matched samples of 42 adults to report three most important personal or public events that happened within their lifetime. They found a bump for important personal memories corresponding to the 20-29-year age period, whereas no bump emerged for important public events.

It is essential that theoretical accounts of the bump need to be tested not only for personal memories but for different types of experiences and information (Janssen, 2015; Koppel \& Berntsen, 2015a; Koppel \& Rubin, 2016). Therefore, life-span retrieval of important public events can be seen as a reasonable testing ground for alternative accounts of the bump. In this study, we aim to provide more comprehensive and comparative data regarding life-span retrieval of important personal and public events to provide further data regarding possible locations of the bump and evaluate the existing accounts. To summarize the novel aspects of our study which improves on earlier studies are the following:

a) We moved beyond the typical task of asking only for the important public events by also asking for public events that were associated with different emotions (e.g., happiest, saddest, most proud). Given that the elicitation of personal events by emotion cues have contributed to our understanding of retrieval of personal important memories (e.g., Berntsen \& Rubin, 2002), we expected that the distributions of public memories associated with different valence (e.g., happiest, saddest) may be critical to evaluating potential accounts of the bump. Furthermore, we expected that cueing public memories associated with 
different emotions would allow us to identify more unique events and test our valence based prediction more broadly. Because most important public events are typically negative in valence, we expected there to be the greatest amount of overlap between these most important and saddest (and possibly most fearful) events.

b) This is the first study to employ a large national sample to compare personal and public important memories in a within-subject design. Almost all studies with nationally representative samples have limited themselves to public events alone and did not address personal memories (e.g., Schuman et al., 1998; Schuman \& Scott, 1989). Moreover, the studies directly comparing important personal and public events used more modest sample sizes (e.g., Koppel \& Bernsten, 2016b). In addition to increasing the reliability of the data in general, this large sample size allowed us to analyze cumulative as well as event-based distributions, given the number of observations at each age-at-event interval.

c) Different from earlier studies, we collected data (ratings) regarding different characteristics of personal as well as public events (e.g., expectancy, relevance to self) to allow testing of existing accounts of the bump.

\section{Method}

\section{Participants}

Data were collected from a large national urban sample ( $n=1205$ ) through face-to-face interviews during November-December 2013. Eight hundred (408 females; age: $18-83$ years, $M=37.60, S D=14.13)$ of these individuals were a nationally representative sample of Turkish urban population, selected according to the Nomenclature of Territorial Units for Statistics (NUTS; Eurostat, 2008). The NUTS is a geographical classification system developed by the European Union based on the socioeconomic statistics of the region. Since the Turkish population is a rather young population, with $50 \%$ of the population 30.7 years and younger (Turkish Statistical Institute, Census, 2014), a nationally representative sample alone would not have been optimal for investigating life-span distributions. Specifically bump-related analyses have typically been focused on data from adults 40 years or older. Therefore, using disproportionate stratification, from the same regions, we recruited another 405 adults who were 40 years or older to increase the representation from older age groups (for a similar approach, see Schuman et al., 1998). Eighty percent of this additional 405 individuals
$\left(M_{\mathrm{age}}=53.46, S D=9.26\right)$ were evenly distributed in the 5 th and 6 th decades of life, and $20 \%$ of this additional group consisted of adults 60 years old and older. Of the total sample of 1,205 , we had to exclude data from 99 participants $(8.2 \%)$ due to extensive missing data and/or incompliance with instructions, leaving us with data from 1,106 adults, of which 653 were above the age of 40 years (312 females).

\section{Materials}

Each participant completed a survey consisting of 51 questions regarding public events, personal events, and demographic variables as well as about family members, socioeconomic indicators such as income, occupation, education, media use and preferences, pastime activities, political affiliation, and religious belief and practices. Here, we only discuss the relevant variables of this survey in detail. The list of questions and ratings are also given in Appendix 1.

The public events questions We asked each participant to name two most important public events and changes (Schuman \& Rodgers, 2004; Schuman \& Scott, 1989) by asking the following question: "In the last 70 years (1940s and onwards) there has been many events and changes in Turkey. Please identify two that you find particularly important in the order you retrieved them." We also asked the same participants to report the happiest, saddest, most proud, most fearful, most hopeful, and most shameful public events in Turkey's last 70 years. For each identified event, participants separately rated how important the event was for themselves as well as for their generation $(1=$ very unimportant, $7=$ very important $)$, the events' valence $(1=$ very negative, $7=$ very positive) and how expected this event was ( $1=$ very unexpected, $5=$ very expected $)$. They also evaluated the relevance of each event to their identity by responding to three items selected from Centrality of Event Scale ("I feel that this event has become a part of my identity"; "This event has become a reference point for the way I understand new experiences"; "This event was a turning point in my life") on a 5 -point scale $(1=$ definitely not, $5=$ definitely yes $)$ (Bernsten \& Rubin, 2006).

The personal events questions Each participant was asked to report their most important, happiest, and saddest personal memories as well as their earliest childhood memory. They were instructed that each memory should be a specific, nonrepeating personal event that occurred at least 1 year ago, lasted a few hours, but no longer than a day. After reporting each memory, participants rated its vividness $(1=$ 
very vague, $5=$ very vivid $)$ and expectancy $(1=$ very unexpected, $5=$ very expected ) on a 5 -point scale, and its valence on a 7 -point scale $(1=$ very negative, $7=$ very positive). They also evaluated the same three statements from the CES questionnaire. Finally, for each event, they reported their age at the time of the event.

\section{Procedure}

The data collection was carried out by a market research company, SAM. The authors held several meetings with the two senior researchers in charge of this project at the market research company regarding details of the sampling and the details of the data collection procedure. In addition, two of the coauthors (A.M. and A.A.E.) held two meetings with data collection supervisors to train them with the questionnaire administration.

Once the household to be contacted was identified, a pair of interviewers (one male, one female) went to the address and randomly identified an adult participant from the household based on the census data. If the particular person agreed, then the survey was read to the participant by the same-sex interviewer. The interviewers were trained to elicit specific answers from respondents without leading them. For instance, if the respondent stated the most important event to be an earthquake or a coup, then the interviewer further prompted the respondent to identify a particular earthquake or coup, respectively.

All participants first completed questions about public events. For the public events, participants always reported the two most important events and answered the relevant questions regarding each separately. The rest of the questions were counterbalanced so that they either started with a positive event (the happiest, saddest, most proud, most fearful, most hopeful, and most shameful) or a negative event (the saddest, happiest, most fearful, most proud, most shameful, and most hopeful). We note here that there was no order effect on either the distributions of public events listed, therefore we do not discuss this issue. Immediately after each event was identified, respondents provided their ratings on various dimensions. Participants were free to list the same public event for two or more categories (e.g., happiest and most proud), but, as we note in the discussion section, such cross-listing was uncommon. Once the event questions were finished, the participants reported their most important, happiest, saddest, and earliest personal memories in the same order. After each personal memory, the same set of event-specific ratings were collected. Finally, they completed the demographic questions. The whole interview lasted approximately 20 to 40 minutes.

\section{Results}

As typical in studies on the bump, the analyses are based on participants 40 years or older. The results are mainly presented as figures depicting life-span retrieval of personal and public events. Plotting retrieval curves requires that a date is assigned to events/memories. For public events, when a range was given, we determined the peak year of the events unfolding during that time period (for a similar approach, see Schuman \& Rodgers, 2004). This occurred for only $9.9 \%$ of the public memories. For both personal and public events, we first determined during which decade of one's life the mentioned event took place. Then, collapsing across all participants, we separately plotted the frequency of mention for important and each emotionally valenced (e.g., most important, happiest, saddest) ${ }^{1}$ personal and public events at each decade of life. Ratings regarding the events (centrality, expectancy, vividness, etc.) were also averaged and plotted similarly across the life span to test alternative accounts. Throughout the manuscript the alpha level used was Bonferroni-adjusted.

\section{Life-span distributions of personal events}

Most important personal events Figure 1 shows that participants retrieved more memories from when they were age 20 to 29 compared to when they were age 10 to 19 , $\chi^{2}(1, N=361)=15.58, p<.001$, and 30 to $39, \chi^{2}(1$, $N=312)=49.28, p<.001$. As can be seen from the inlet, the same pattern was observed for the participants in their 40s, 50s, and 60s.

We categorized each event as positive or negative based on the ratings participants gave on a 7-point scale. An event was categorized as negative if it received a rating of 3 or less and as positive if it received a rating of 5 or higher. As seen in Fig. 2, a bump peaking at age interval 20-29 emerged for positive memories; participants reported more memories from that age interval than any other interval, $\chi^{2}(1) \mathrm{s}>29.78, p \mathrm{~s}<.001$. No bump emerged for negative memories, $\chi^{2}(1) \mathrm{s}<1.45, p \mathrm{~s}>$ .257 .

Happiest and saddest personal events Figure 3 shows the retrieval distributions for happiest and saddest personal events. For happiest events there was a clear bump;

\footnotetext{
${ }^{1}$ We did not plot the data coming from before participants were born, which constituted approximately $1 \%$ of the data. However, we did not discard these data points from the main descriptives.
} 


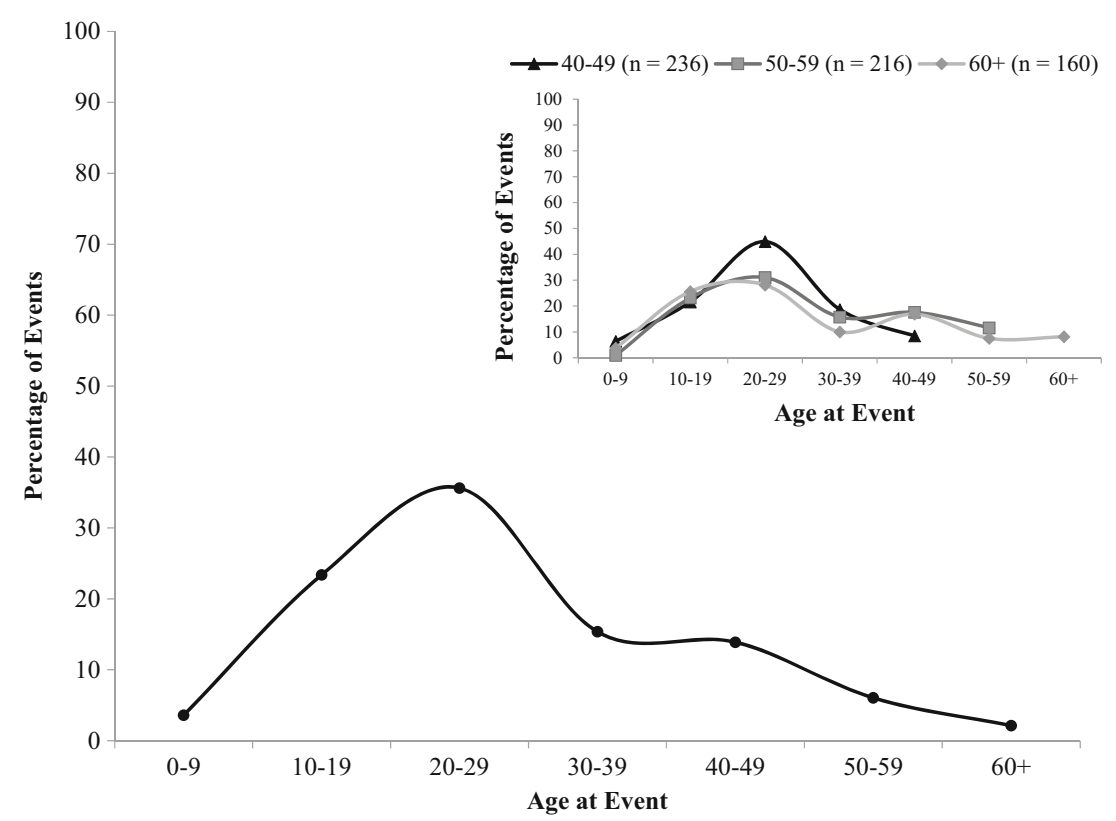

Fig. 1 The life-span retrieval curve for the most important personal events

happiest memories were more likely to come from the 20-29 age interval (42\%) compared to the 10-19 (21\%), $\chi^{2}(1, N=372)=85.17, p<.001$, and $30-39(16 \%)$, $\chi^{2}(1, N=381)=74.96, p<.001$, intervals. As can be seen in the inlet in Fig. 3, the same pattern was seen across all age groups.

For saddest personal memories, however, there was no bump corresponding to youth. Rather, a shallower bump corresponding to $30-49$ age intervals emerged; more memories were reported from $30-39$ and 40-49 intervals compared to other age intervals (all $\chi^{2}>12.51$, all $p$ s $>.001$, with no difference between these two age intervals $\left(\chi^{2}<1\right)$. As can be seen from the inlet, saddest memories were more often retrieved from the preceding 2 decades of life for all three age groups. To determine whether this late bump for saddest personal events may have been linked to the possible timing of particular sad events in a prototypical life, we first looked at the distribution of events reported during the 30-49 period. For both the 30 39 and 40-49 age periods, the most often reported saddest

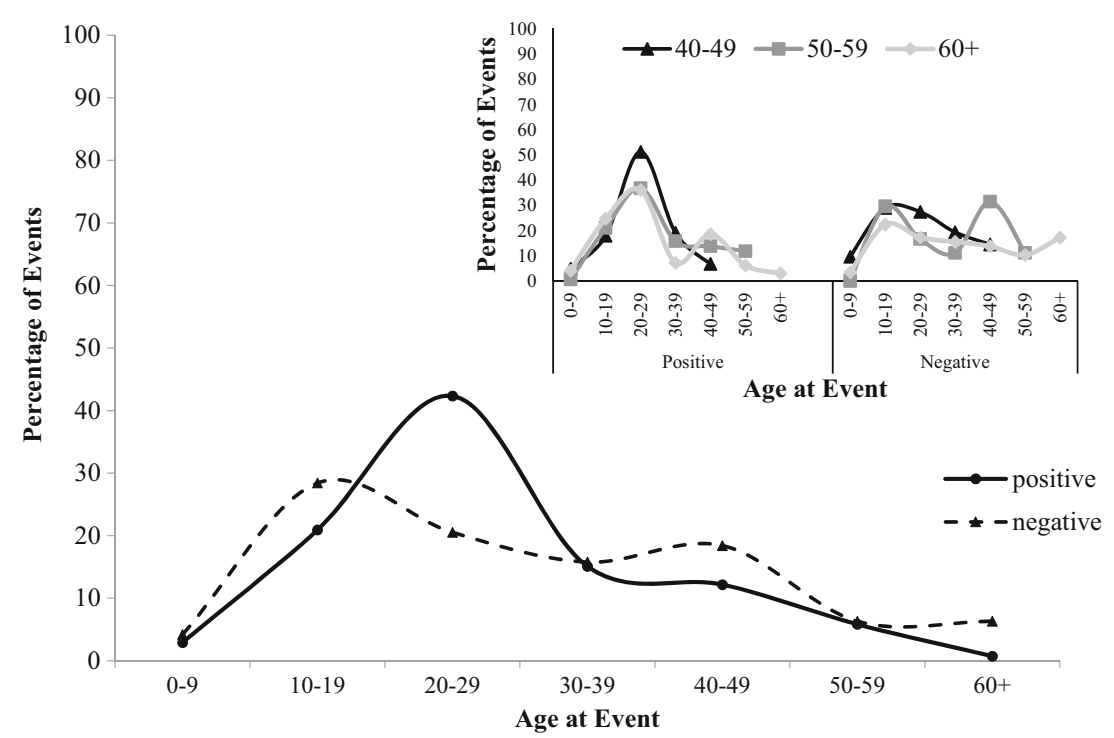

Fig. 2 The life-span retrieval curve for positive versus negative most important personal events 


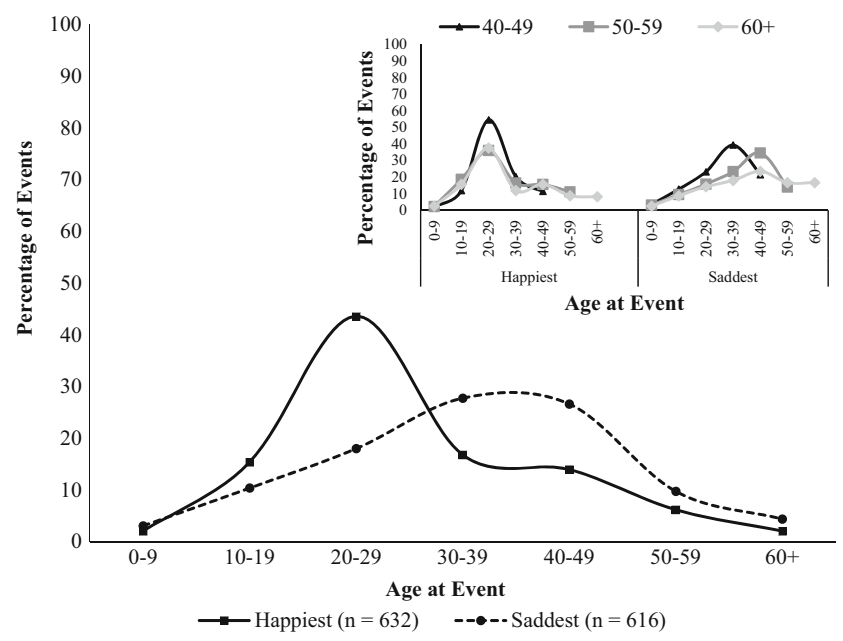

Fig. 3 The life-span retrieval curve for happiest and saddest personal memories

event was the loss of a parent (41.6 and 41.50, respectively), followed by the loss of spouse (around 19\% in both age groups). Overall, these two saddest events accounted for approximately $60 \%$ of the bump events in Fig. 3. When we inspected age-at-event distributions of these two events separately, we demonstrated that approximately $60 \%$ of the parental deaths occurred during the 30-49 age interval. In a similar vein, $50 \%$ of spousal losses occurred during the same age period. Thus, rather than being a simple recency effect, the late bump observed for saddest memories seem to be heavily influenced by the actual content and timing of events.

\section{What accounts for the retrieval distributions of personal events?}

In order to evaluate alternative accounts of the distributions, we collected a number of ratings from each participant regarding how unique, how vivid, how novel, and how central (to identity) the reported events were.

The overall pattern of results showing a bump at the 20-29 age interval for most important and happiest memories and the absence of a bump for the saddest memories is most consistent with the cultural lifescript account. This claim is further supported by the substantial overlap of the content of the most important and happiest memories listed by the participants (presented in Table 1) and the Turkish life-script events obtained in other studies (Erdoğan et al., 2008; Tekcan et al., 2012). Four of the five most frequently listed most important personal events and all of the five happiest events were life-script events of Turkish older adults (Tekcan et al., 2012), corresponding to $40 \%$ of the most important and $58 \%$ of the happiest events.
We also analyzed the ratings as a function of age-at-event (see Table 2). For most important memories, there was an effect of age at event on expectancy ratings, $F(6,605)=$ 3.67, $M S E=2.33, p=.001, \eta_{\mathrm{p}}^{2}=.03$; memories from the 20-29 interval $(M=3.51, S D=1.46)$ were more expected than memories from the $30-39(M=2.82, S D=1.61)$ and $60+(M=2.23, S D=1.54)$ intervals $(d \mathrm{~s}=.47$ and .85 , respectively). Similarly, there was an age-at-event effect on expectancy ratings for happiest events as well, $F(6,623)=3.87$, $M S E=1.35, p=.001, \eta_{\mathrm{p}}{ }^{2}=.04$; memories from the 20-29 interval were more expected $(M=4.14, S D=1.11)$ than memories from the $0-9(M=3.15, S D=1.41)$ and the $30-39(M=$ $3.67, S D=1.19)$ intervals ( $d s=.78$ and .41 , respectively). No such effect was observed for saddest events. Overall, these findings are also in line with the basic tenet of the life-script account that life scripts provide a framework guiding the retrieval of personal events.

Although there was an age-at-event effect for vividness ratings of the most important memories, $F(6,605)=2.79$, $M S E=.53, p<.05, \eta_{\mathrm{p}}^{2}=.03$, the only significant pairwise difference was that the memories coming from the 40-49 interval were rated as more vivid $(M=4.76, S D=.53)$ than memories from the 10-19 $(M=4.48, S D=.94)$ interval, $d=$ .37. For happiest memories, the significant effect of age at event on vividness ratings, $F(6,624)=3.04, M S E=.37, p<$ $.05, \eta_{\mathrm{p}}{ }^{2}=.03$, was driven by the fact that memories coming from the 0-9 $(M=4.08, S D=.95)$ period were rated less vivid than memories from $40-49(M=4.72, S D=.54)$ and $60+(M=$ $4.92, S D=.61)$ intervals, $(d \mathrm{~s}=.83$ and 1.05 , respectively). No age-at-event effect on vividness was observed for saddest events. Moreover, there was no effect of age-at-event effect on expectedness or uniqueness of memories/events for the most important and the happiest events. Overall, these findings are in disagreement with the cognitive hypothesis because the events in the bump were considered neither more vivid nor more novel.

Age at event did not affect mean CES ratings for happiest personal events, $F(6,629)=1.364, M S E=$ $.82, p=.23, \eta_{\mathrm{p}}{ }^{2}=.01$. In other words, bump memories were not given higher CES ratings than events from other age intervals. For most important memories, although there was a main effect of age at event, $F(6$, $611)=2.16, M S E=1.00, p=.044, \eta_{\mathrm{p}}{ }^{2}=.02$, none of the pairwise comparisons were significant. For saddest events, there was an effect of age at event on the centrality of events scale scores, $F(6,614)=2.51, M S E$ $=1.16, p=.02, \eta_{\mathrm{p}}{ }^{2}=.02$; post hoc test showed that memories coming from $40-49$ age-at-event interval $(M$ $=4.18, S D=.91)$ were rated higher scores compared to memories coming from 10-19 age-at-event interval ( $M$ $=3.66, S D=1.19), d=.49$. Saddest events showed a flatter bump corresponding to the 5th and 6th decades of life, and the life-span distribution of CES ratings of 
Table 1 The top five most important, happiest and saddest personal events

\begin{tabular}{lrlrc}
\hline Most important event & $\%$ & Happiest Event & $\%$ & Saddest Event \\
\hline Marriage & 13.1 & Having children & 29.9 & Death of a parent \\
Having children & 13.0 & Getting married & 14.8 & Death of a spouse \\
Health problems & 8.5 & Getting into college & 5.0 & Health problems \\
Getting into college & 5.4 & Getting a job & 4.2 & Accident \\
Meeting (future) spouse & 3.3 & Child's marriage & 3.8 & Loss of job \\
\hline
\end{tabular}

for the saddest events parallel that. Thus, an identitymemory link may be present for saddest memories, which largely consisted of illness/death of parents of other family members.

\section{Life-span distributions of public events}

Most important public events Figure 4 shows the lifespan retrieval curve for the most important public events $(n=419)$. No clear bump emerged for most important public events; there was a relatively flat distribution with a plateau ranging from young through middle adulthood. More events were reported from the 20-29, 30-39, and 40-49 intervals than the remaining age intervals; all $\chi^{2}(1) \mathrm{s} \geq 4.11$, all $p \mathrm{~s} \leq .043$. Separate retrieval curves of participants in their $40 \mathrm{~s}, 50 \mathrm{~s}$, and $60 \mathrm{~s}$ also showed a relatively flat distribution, suggesting that once a young adult, people are equally likely to retrieve an event from different periods of their lives.

As in personal memories, we also grouped most important public events by their rated valence, using the same criteria as before. As can be seen in Fig. 5, the pattern for positive $(n=$ $99)$ and negative $(n=303)$ public events were similar. ${ }^{2}$

Happiest and saddest public events Figure 6 depicts the lifespan retrieval distribution for the happiest $(n=276)$ and saddest $(n=299)$ public events. The distribution is very similar for both types of events and are characterized by a late peak in the 5th decade of life and somewhat extending to the 6th decade. Analyses showed that more events were reported from these two periods than others, $\chi^{2}(1) \mathrm{s} \geq 11.90$, all $p \mathrm{~s} \leq .001$, and all $\chi^{2}(1) \mathrm{s} \geq 8.60$, all $p \mathrm{~s} \leq .003$, for happiest and saddest events, respectively. However, inspection of the separate dis-

\footnotetext{
$\overline{2}$ Relatively small number of participants $(n=99)$ reported a positively rated most important event. When these were broken down across the three age groups, there were small number participants at each age group and age-atevent period which affected the reliability of the distributions. Therefore, we do not to present separate age group distributions as inlets for this particular graph.
}

tributions based on each age group (see inlet) revealed a strong recency effect for both categories, with approximately $50 \%$ to $60 \%$ of the events coming from the last decade of life.

Most proud, most fearful, most hopeful, and most shameful events The life-span retrieval curves for the most proud ( $n$ $=235)$, most shameful $(n=234)$, most hopeful $(n=195)$ and most fearful $(n=174)$ events are presented in Fig. 7.

In all four categories of events, the greatest proportion of events reported came from the 5th decade of life, all $\chi^{2}(1) \mathrm{s} \geq 8.98$, all $p \mathrm{~s} \leq .003$. However, a true bump was observed only for the most fearful memories; for the remaining three categories, the percentage of events reported from the 40-49 and 50-59 intervals were not significantly different (all $p \mathrm{~s}>.05$ ) for the most proud, most shameful and most hopeful events. Separate distributions for each age group clearly showed that this late bump was in fact due to a strong recency effect.

\section{What accounts for the retrieval distributions of public events?}

For the most important, happiest, and saddest events, age at event had no effect on either the CES or the expectancy ratings (all $F \mathrm{~s} \leq 1.26$, all $p \mathrm{~s} \geq .27$ ). Similar results were obtained for most proud, most fearful, most hopeful, and most shameful events, except for the most fearful public events where there was an ageat-event effect on CES, $F(7,226)=2.52, M S E=1.03$, $p=.017, \eta_{\mathrm{p}}{ }^{2}=.07$; events from the $10-19$ decade $(M$ $=4.18, S D=.77)$ were rated more central to identity than those from the 50-59 decade $(M=3.01, S D=$ $1.01)$. It must be noted that $66.7 \%$ of the events reported from the 10-19 interval referred to the September 12 military coup, and ratings related to this event likely increased the centrality scores for that decade. These results showed that the ratings used as measures of the identity and the cognitive accounts followed a different pattern than the public event mentions across different age-at-event points. 
Table 2 Means and standard deviations for Centrality of Event Scale (CES) Items, Vividness and Expectancy Ratings for Personal Memories

\begin{tabular}{|c|c|c|c|c|c|c|c|c|c|}
\hline \multirow[b]{2}{*}{ Age-at-event } & \multicolumn{3}{|c|}{ Most important } & \multicolumn{3}{|l|}{ Happiest } & \multicolumn{3}{|l|}{ Saddest } \\
\hline & $\begin{array}{l}\text { CES } \\
M(S D)\end{array}$ & $\begin{array}{l}\text { Vividness } \\
M(S D)\end{array}$ & $\begin{array}{l}\text { Expectancy } \\
M(S D)\end{array}$ & $\begin{array}{l}\text { CES } \\
M(S D)\end{array}$ & $\begin{array}{l}\text { Vividness } \\
M(S D)\end{array}$ & $\begin{array}{l}\text { Expectancy } \\
M(S D)\end{array}$ & $\begin{array}{l}\text { CES } \\
M(S D)\end{array}$ & $\begin{array}{l}\text { Vividness } \\
M(S D)\end{array}$ & $\begin{array}{l}\text { Expectancy } \\
M(S D)\end{array}$ \\
\hline $0-9$ & $3.77(.81)$ & $4.27(.93)$ & $3.05(1.70)$ & $4.07(.87)$ & $4.08(.95)$ & $3.15(1.41)$ & $4.12(.94)$ & $4.47(.96)$ & $1.89(.99)$ \\
\hline $10-19$ & $3.99(1.19)$ & $4.48(.94)$ & 3.09 (1.44) & $4.37(.92)$ & $4.67(.76)$ & $4.08(1.19)$ & $3.66(1.19)$ & $4.44(.83)$ & $2.17(1.24)$ \\
\hline $20-29$ & $4.29(.89)$ & $4.64(.66)$ & $3.51(1.46)$ & $4.41(.84)$ & $4.63(.52)$ & $4.14(1.11)$ & $3.86(1.18)$ & $4.63(.71)$ & $2.08(1.35)$ \\
\hline $30-39$ & $4.18(1.05)$ & $4.62(.73)$ & $2.82(1.61)$ & $4.16(1.01)$ & $4.62(.67)$ & $3.67(1.19)$ & $3.94(1.13)$ & $4.62(.82)$ & $1.95(1.36)$ \\
\hline $40-49$ & $4.24(.91)$ & $4.76(.53)$ & $3.05(1.65)$ & $4.24(.91)$ & $4.72(.54)$ & $3.80(1.23)$ & $4.18(.91)$ & $4.74(.52)$ & $1.87(1.24)$ \\
\hline $50-59$ & $4.26(1.07)$ & $4.61(.46)$ & $3.14(1.60)$ & $4.25(.94)$ & $4.64(.55)$ & $4.10(1.14)$ & $4.11(.86)$ & $4.70(.77)$ & $2.08(1.41)$ \\
\hline $60+$ & $4.48(.37)$ & $4.69(.48)$ & $2.23(1.54)$ & $4.38(.77)$ & $4.92(.61)$ & $3.75(1.29)$ & $4.25(1.08)$ & $4.81(.48)$ & $1.67(1.97)$ \\
\hline
\end{tabular}

\section{Event-based distributions of the most important public events}

When life-span retrieval distribution are based on collapsing all events mentioned by the participants, it necessarily includes events that are mentioned by only a small proportion of the sample. This raises two potential issues. First, when event-based distributions are analyzed, it means that there are very few observations on which to base age-at-event comparisons, even with larger national samples such as ours. Second, studies on collective memories overwhelmingly showed that two or three public events dominate the collective memory of a nation (Schuman et al., 1998; Schuman \& Scott, 1989). In other words, in previous studies there were a few

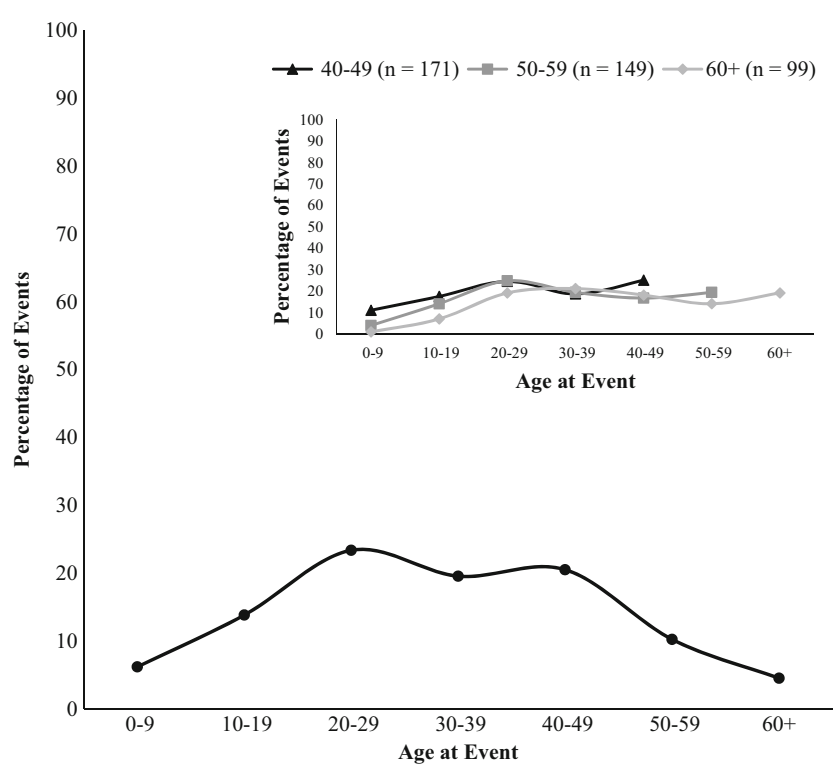

Fig. 4 The life-span retrieval curve for the most important public events events that have been mentioned by a large portion of the sample, followed by several events that are mentioned by a much lower proportion (typically, $5 \%$ or less). It is possible that distributions based on collapsing all mentioned events might mask bumps that might be observed for highfrequency events. Koppel (2013) tested the idea that frequency of mention might be related to the emergence of a bump (i.e., the bump is more likely to be observed for more frequently mentioned events) and found no correlation between the two.

We tested this idea by constructing life-span retrieval distributions for high-frequency events in comparison to the lower frequency events. The most frequently mentioned 10 events and the associated percentages of mention are provided in Table 3. Two events dominate the Turkish collective memory: The September 12 military coup (25.3\%) and the 1999 Marmara earthquake (18.1\%; see Appendix 2 for description of these events), together consisting $43.4 \%$ of the responses. ${ }^{3}$ As can be seen from this table, there is a sudden drop in the frequency of mention of the remaining events. Figure 8 shows the retrieval distribution for the top two events along with the remaining eight events in the top 10. A clear bump corresponding to 20-29 interval emerged for the top two events, whereas a later bump peaking at the 40-49 interval emerged for the remaining eight event.

Approximately $70 \%$ of the participants who mentioned the September 12 military coup as the most important event were either in their second (10-19) or third (20-29) decade of life at the time of the event; this event was reported more frequently by individuals

\footnotetext{
${ }^{3}$ Each one of the remaining events in the most important category were reported by fewer than 30 participants, which rendered it impossible to obtain reliable life-span distribution curves.
} 


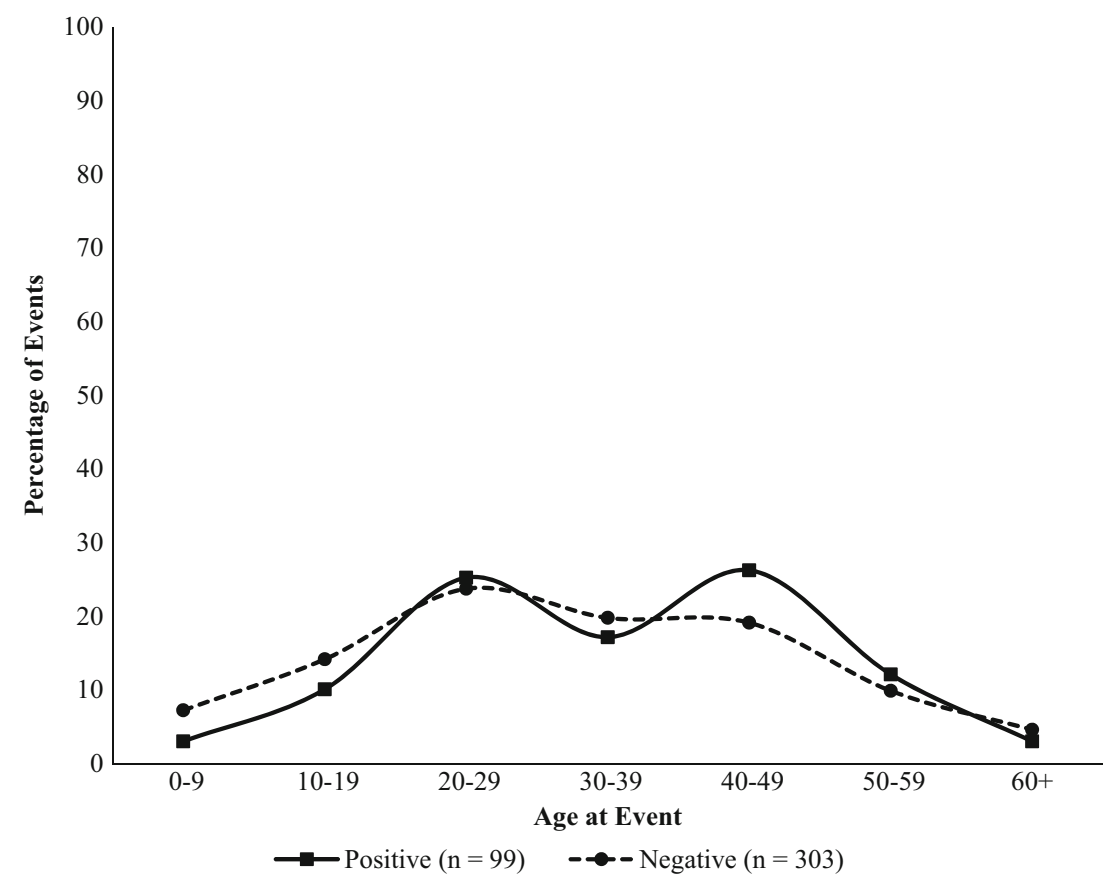

Fig. 5 The life-span retrieval curve for the most important positive versus negative public events

in these two age groups than all other age intervals, all $\chi^{2}(1) \mathrm{s} \geq 5.67$, all $p \mathrm{~s} \leq .017$. As for the second event, $72 \%$ of the participants mentioning the Marmara earthquake was either in their third (20-29) or fourth decade of life (30-39). Analyses showed that these two groups were more likely to mention this event than participants in other age intervals, all $\chi^{2}(1) \mathrm{s} \geq 7.04$, all $p \mathrm{~s} \leq .008$. To determine whether the bump for the September 12

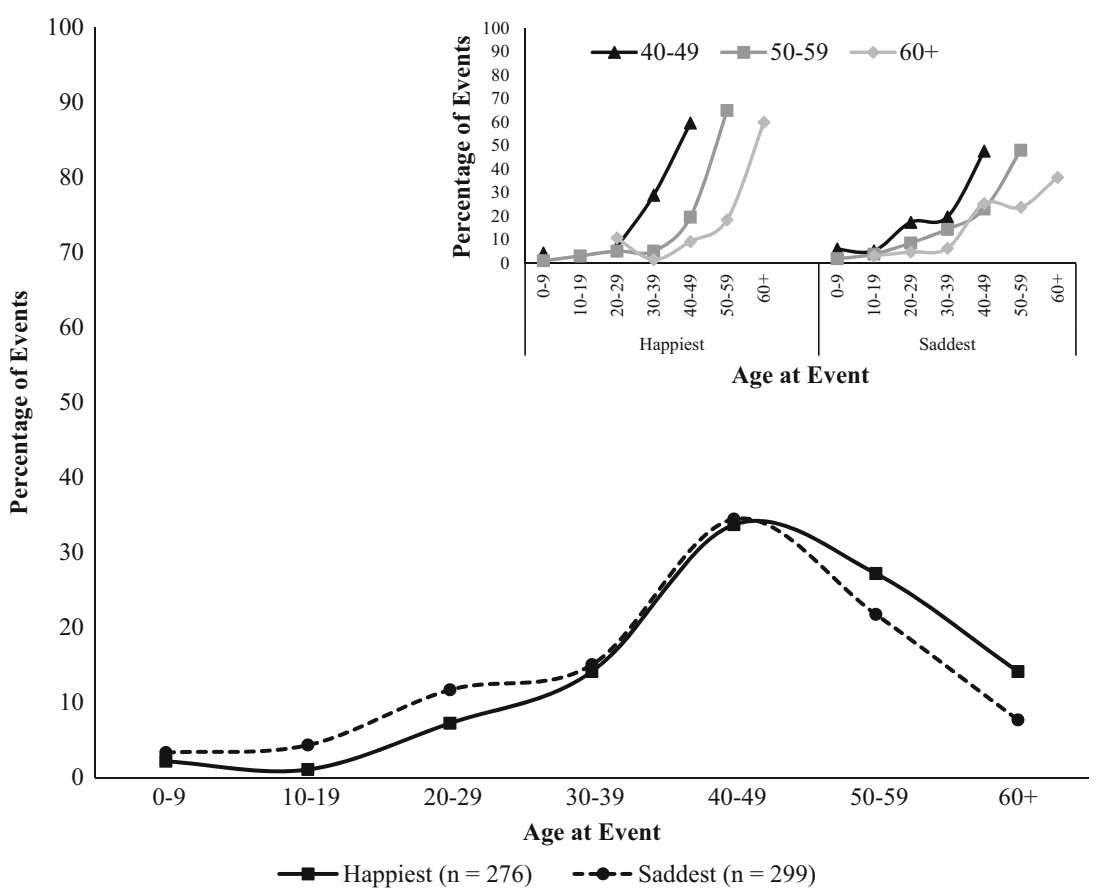

Fig. 6 The life-span retrieval curve for the happiest and saddest public events 


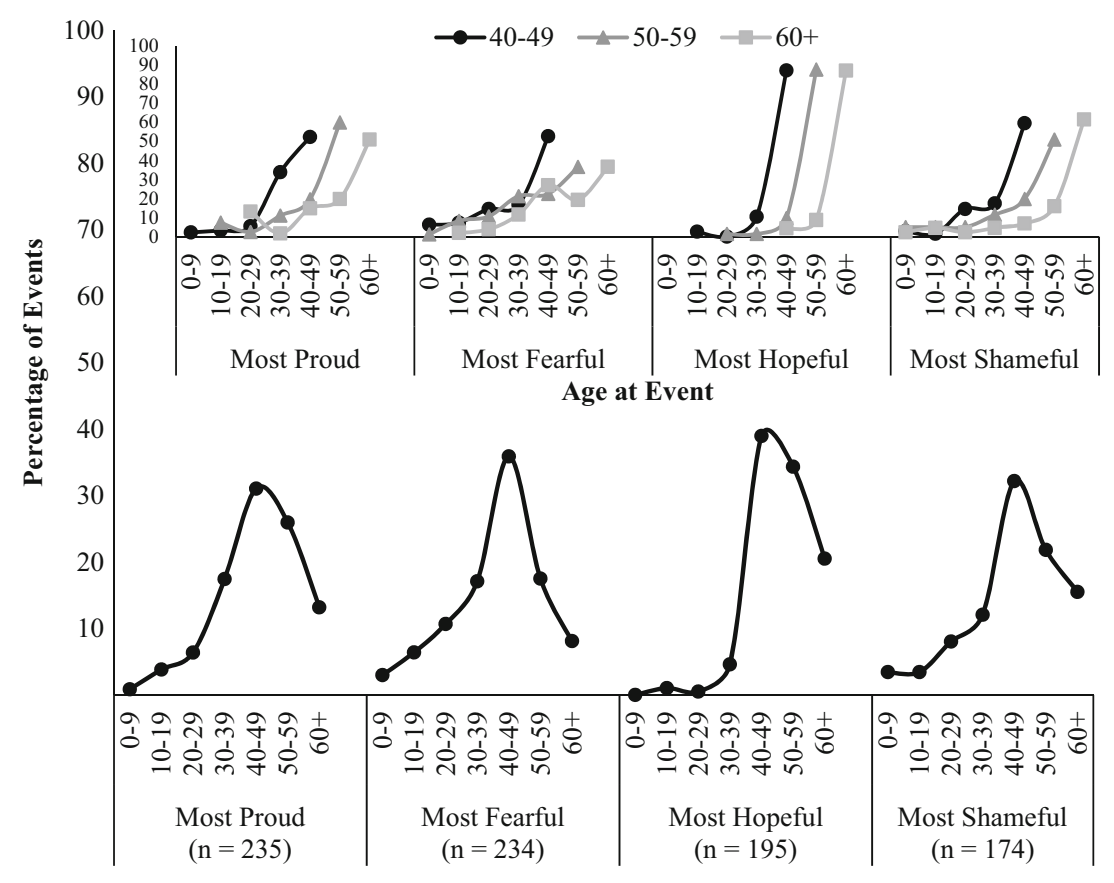

Age at Event

Fig. 7 The life-span retrieval curves for the most proud, fearful, hopeful, and shameful public events

military coup was driven by the perceived valence, we compared the retrieval pattern separately for participants who rated it positive and those who rated it negative. A bump emerged for both groups, with a peak at 20-29 for the positive group and a wider peak extending to both $10-19$ and $20-29$ age periods. This comparison was not possible for the Marmara earthquake because there were very few participants who rated it positive.

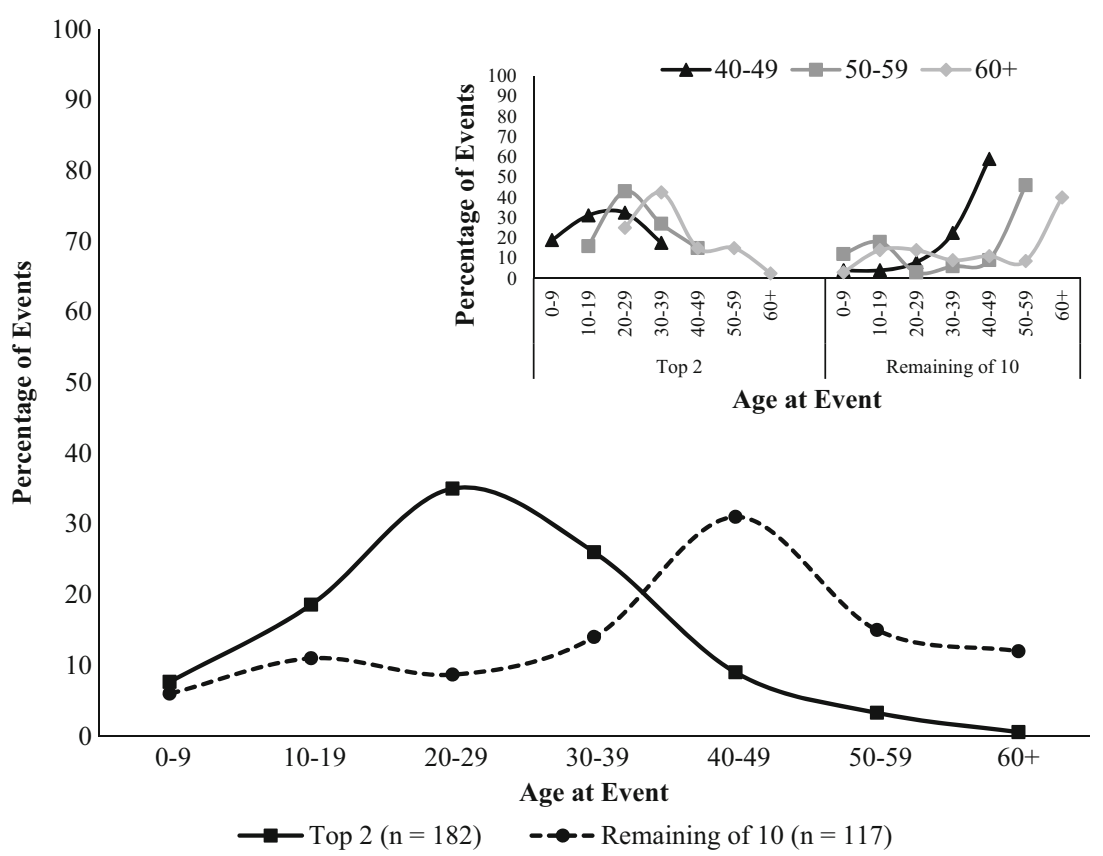

Fig. 8 The distribution of top two and remaining eight most important events 
Analyses also showed that the CES and expectancy ratings did not vary across age-at-event intervals for either the September 12 military coup, $F(4,101)=1.36, M S E=1.41$, $p=.25, \eta_{\mathrm{p}}{ }^{2}=.05$, and $F(4,97)=1.11, M S E=2.30, p=.36$, $\eta_{\mathrm{p}}{ }^{2}=.04$, or the Marmara earthquake, $F(4,71)=.80$, MSE $=$ $1.21, p=.53, \eta_{\mathrm{p}}{ }^{2}=.04$., and $F(4,69)=.80, M S E=1.43, p=$ $.53, \eta_{\mathrm{p}}{ }^{2}=.04$, respectively, failing to support either the identity or cognitive accounts of the bump.

\section{Discussion}

While there has been considerable research on the reminiscence bump, this study was first to use a large national sample to investigate life-span retrieval of public and personal events. To be able to better describe the conditions under which a bump for public events emerge and differentiate among various accounts for the bump, in addition to most important memories, we also collected personal and public events cued with different emotions. To summarize our main findings, first, we found a strong bump corresponding to the third decade of life for most important and happiest personal memories. Second, no bump emerged for public events when collapsed across events. However, a bump corresponding to early adulthood emerged only for highimpact events that dominated the Turkish collective memory, the September 12 military coup (1980) and the Marmara earthquake (1999). Third, the distributions for the remaining most important public events as well as public events associated with different valence (e.g., happiest, most proud) showed very robust recency effects. While the findings with regard to the distribution of personal events fit well with the cultural life-script account of the bump (e.g., Berntsen \& Rubin, 2004), none of the existing accounts are able to explain the patterns we found for public events. Therefore, our findings add to the growing body of work that argue that the reminiscence bump does not reflect a unitary memory phenomenon (Koppel \& Bernsten, 2015a; Koppel \& Rubin, 2016), and furthermore suggests that retrieval of important personal and public events are likely to be governed by different search mechanisms. We discuss our findings in more detail below.

\section{Retrieval of personal events}

We found a robust bump corresponding to the third decade of life for most important and happiest personal memories. The apparent bump for the 5 th decade of life for saddest memories reflected the fact that two negative events - death of a parent and death of spouse - are more likely to occur during middle to late adulthood. Moreover, the bump emerged for most important memories rated positive by the participants but not for those rated negative. All of these patterns held for the three age groups (i.e., participants in their $40 \mathrm{~s}, 50 \mathrm{~s}$, and $60+$ ). The remarkable similarity of the distribution of important, happiest and saddest memories clearly support the robustness, consistency, and culture-independence of the bump phenomenon for important personal memories (Conway et al., 2005).

These results closely replicate earlier findings on life-span retrieval of important autobiographical memories (e.g., Berntsen \& Rubin, 2002; Koppel \& Berntsen, 2015a; Rubin $\&$ Berntsen, 2003). These set of findings are best explained by the cultural life-script account (Berntsen \& Rubin, 2004). First, although all accounts are in line with the finding of a peak in the 3rd decade of life, only the life-script account is able to explain the dissociation between the happiest and the saddest memories. This account suggests that life scripts, which are dominated by positive events that are expected to occur during one's youth, are used as guides in retrieval of positive autobiographical experiences. When people are asked to remember their happiest personal memories, they might direct themselves to the period when such happy memories are mostly expected to occur. Given that a similarly reliable life script does not exist for negative personal memories, recall of saddest or other negative autobiographical memories do not benefit from such a retrieval help (Berntsen \& Rubin, 2004; Koppel \& Berntsen, 2015a). Second, the substantial overlap between most important as well as happiest memories with life-script events support the claim that cultural life-scripts guide recall of important autobiographical events (e.g., Bohn \& Berntsen, 2013). In addition, the finding that most important and happiest events falling into the bump period were rated as more expected than events from other intervals provides additional support for the life-script account; if life-scripts guide recall of important personal events, then those events should indeed be more expected than others. It is worth noting that although the shallow bump observed for saddest personal events appears to be based on recency, it is likely that the content and the typical age at events for these particular events (e.g., death of a parent) were the major contributors to this pattern. This is in line with findings from lifescript and autobiographical memory studies, which found a linear increase across the life span when older adults were asked to report their saddest memory (Berntsen \& Rubin, 2002). Data from studies addressing expected ages for saddest life events also reported a steady increase after age 30 (Rubin \& Berntsen, 2003).

As noted above, the effects of valence on the retrieval distributions cannot be explained by other accounts. Moreover, comparison of the ratings for events from different age-atevent intervals did not support any of the alternative accounts of the bump. With regard to the identity account, most important and happiest bump memories were not considered more central to identity than memories from other intervals. As to the cognitive account, ratings of vividness and expectancy 
were not higher for bump memories compared to memories from other intervals. We therefore conclude that the life-script account is the most satisfactory explanation for the distribution of important personal memories.

\section{Retrieval of public events}

When collapsed across all mentioned events, there was no bump for most important events. However, when event based distributions were analyzed, a bump corresponding to the $3 \mathrm{rd}$ decade of life was observed only for the two most frequently mentioned events in the Turkish collective memory. This finding suggests that reminiscence bump may emerge only for high-impact public events that are part of the collective memory of a society. Our results showed that these two public events indeed dominated the Turkish collective memory: the September 12 military coup (1980) and the Marmara earthquake (1999). These events were not only mentioned by close to half of the participants (43\%), but there was also a sudden drop in the frequency of mention for the immediately following events (from $18 \%$ to $7 \%$ ). In addition, several studies from our lab, conducted in the past 10 years, showed that these two events consistently emerged as part of the most important events in Turkey's past 70 years, by different age groups (e.g., Tekcan \& Tartar, 2008). Thus, we argue that a bump may emerge only for high impact, highly memorable events.

We also have to note that expectancy, centrality, personal importance, and generational importance ratings failed to support either the identity or the cognitive explanation. These ratings were not different for participants who were in their late adolescence or early adulthood than those who were younger and older. Although there is no clear evidence that life scripts exist for public events (Janssen, 2015; Koppel \& Berntsen, 2015b) the concept of youth bias, which refers to a cognitive bias in which individuals expect important public events to take place during one's late adolescence/early adulthood, is relevant (Koppel \& Berntsen, 2014, 2016a). Research not only showed that people disproportionately expect the most important public event in a typical life to occur during an individual's young adulthood (Koppel \& Berntsen, 2014) but also extended this effect to specific type of public events such as deaths of public figures, U.S. presidential elections, and sporting events (Koppel \& Berntsen, 2016a). Most importantly, they found a correlation between people's expectations about the timing of important public events and the timing of most important public event in the same individuals' lives, suggesting that youth bias might serve as a retrieval frame for public events. One significant issue was that this latter finding was true only for sporting events, and not for death of public figures or U.S. presidential elections. This was, they argued, because for the other two events one or two major events would lead to high recall overriding any effect of youth bias (Koppel \& Berntsen, 2016a). These findings are potentially very important because they present a novel conceptual explanation of the bump for public events. More importantly, if supported further empirically, this would suggest that a very similar process (i.e., expectations) is responsible for the life-span retrieval of personal and public events.

We also note that although both Koppel and Berntsen (2016a) and we assign critical role to impact or salience of the public events; we all agree that events with widespread impact may dominate recall of public events and influence age-at-event effects. The difference lies in the fact that we found that event impact allows the bump to manifest itself, whereas Koppel and Berntsen (2016a) found that event impact obscures the bump.

Koppel (2013) had previously tested the idea that memorability may be a key factor moderating whether a bump emerges for public events, but his analyses of existing data had not supported this contention. We believe that his operationalization of memorability may have been partially responsible for this lack of an effect. In his analyses, an event was considered highly memorable if it fell in the top half of the events mentioned in a given study on the basis of frequency of mention. Depending on the number of the events generated, this cut-off would allow events that were mentioned by few participants to be included in the highly memorable group, and this, in turn, may have caused the bump to disappear. For instance, if we had used Koppel's criteria, we would have had to include events that were reported only by $4 \%$ of our participants (see Table 3 ); it is hard to argue that such events reflect a nation's genuine collective memory.

It could also be argued that our findings contradict those of Koppel and Berntsen (2016b) who showed that

Table 3 The most frequently reported 10 public events

\begin{tabular}{llr}
\hline Event & Frequency & $\%$ \\
\hline Sept. 12, military coup (1980) & 106 & 25.3 \\
Marmara earthquake (1999) & 76 & 18.1 \\
Van earthquake (2011) & 29 & 6.9 \\
Gezi protests (2013) & 22 & 5.3 \\
Peace process (2013) & 16 & 3.8 \\
May 27, military coup (1960) & 14 & 3.3 \\
Cyprus military operation (1974) & 11 & 2.6 \\
AKP's coming to power (2002) & 9 & 2.1 \\
Madımak Hotel arson (1993) & 8 & 1.9 \\
Maraș events (1978) & 8 & 1.9 \\
\hline
\end{tabular}


there was no bump even when they focused on the two dominant events in the Danish collective memory. However, it should be noted that their small sample size, with the most frequently listed event being reported by only 13 individuals, renders it impossible to look at event-based age-at-event distributions. This is unfortunate given that the bump was revealed only in the event-based distributions both in the current study and in earlier work (e.g., Schuman \& Scott , 1989). In this regard, we must emphasize the importance of employing large samples that allow exploring event-based distributions and age at the time of testing. As can be seen in Fig. 7, what appeared to be legitimate bumps were revealed to be recency effects when age at the time of testing was taken into account.

Another difference between Koppel and Bernsten (2016b) and our study may be related to qualities of events reported. Specifically, the Danish collective memory seems to lack dominant national events, with the top two responses, the fall of the Berlin Wall and $9 / 11$, constituting $11 \%$ and $9 \%$ of the responses, respectively. In this regard, the Danish collective memory also seems to be different than that of other nations, like the United States, Germany, and Japan (e.g., Schuman et al., 1998; Schuman \& Rodgers, 1989) as well as that of Turkey. Although we emphasize event dominance with regard to the differences in findings of the two studies, it is also possible that the instability of Turkey, characterized by frequent coups, coup attempts, assassinations as well as numerous high-toll earthquakes, may differentiate it from Denmark, a relatively stable country which seems to lacks dominant events. In Turkey, there may be far too many critical public events, some of which are replaced by newer ones even before being consolidated into collective memory. Accordingly, a bump for public events might be less likely to emerge for countries where such important public events occur with some regularity, and a clear bump would be more likely to emerge for countries where such events are few and far between. Although there are no studies directly addressing this issue, existing evidence do not support this possibility. For instance, lack of a bump for important public events in the Danish sample of Koppel and Berntsen (2016a) goes against this view. Moreover, it might be argued that if there are only a few events that are very important for a nation, it is possible that, regardless of age at event, most people would cite those few events as the most important events, leading to a relatively flat lifespan retrieval distribution. Indeed, this was a common pattern reported by Koppel (2013). Finally, crosssectional data from Turkey showed that the same few events (those for which the bump emerged in the present study) were consistently reported as the most important events across time (e.g., Tekcan \& Tartar, 2008). Clearly, the potential role of event dominance, stability, or other potential factors with regard to the bump are issues that are in need of empirical scrutiny.

We argue that one key characteristic of bump events is that they are highly memorable events. It is possible that these events can be construed as transitional events. Brown and Lee (2010) claims that public events may play a role in organization of autobiographical memory to the degree that they cause changes in the fabric of daily life (e.g., Brown \& Lee, 2010). Specifically, they distinguish between the material ("This event changed my material circumstances"; "This event changed the activities I engage in"; "This event changed the things I own") and psychological impact of an event, claiming that the former changes the fabric of daily life more (Svob, Brown, Reddon, Uzer, \& Lee, 2014). Although we do not yet have data directly addressing this issue, both the September 12 military coup and the Marmara earthquake are viable candidates. As a result of the coup, 50 people were executed; more than 600,000 people were taken into custody; 30.000 people fled Turkey; more than 1,500,000 people were blacklisted; 230,000 people were tried; and newspapers were not published for a year. The 1999 Marmara earthquake hit the Marmara region of Turkey with a magnitude of 7.5. As a result, 16 million people were affected to different degrees; 17.480 people died, 23.781 injured, and more than 285.000 homes damaged.

With regard to the retrieval distributions for public events cued with different emotions, there were clear recency effects such that participants in all age groups overwhelmingly reported events from the most recent decade of their lives. One possibility is that these events (e.g., happiest, most proud) in Turkey's history might have actually taken place within the most recent decade. Given that Turkey is one of those countries where negative public events occur with some regularity with lasting effects on the nation (a number of military coups or coup attempts, several assassinations, terrorist attacks), along with some positive events (Nobel prizes in literature and chemistry, becoming third in the World Soccer Championship, winning the Eurovision song contest), this hypothesis is difficult to maintain. Rather, we suggest that this finding is a reflection of a chronological search mechanism participants adopt, starting from the 
recent times going backward. As such, when participants are asked to report happiest, most proud public events, they do not go back to their "happy public events" or "most proud public events" pool and then search and select within that pool. This possibility is further bolstered by the fact that individuals have greater difficulty identifying public events associated with certain more specific emotions (e.g., most proud, most shameful, most fearful) as opposed to most important ones; they may not readily have such public event pools. Instead, they may start with the most recent public event and go back until they find an event that fits the characterization of "happiest" or "most proud." Indeed, when the findings regarding the most important public events are considered (i.e., a marked recency effect for events other than the two most frequently mentioned events), this chronological retrieval mechanisms might be the default mechanism for public events. This possibility is further strengthened by the greater overlap between the most important and saddest $(14.80 \%)$ as well as the most important and the most fearful $(8.83 \%)$ memories. Interestingly in both cases more than $65 \%$ of the overlap was driven by the top two events, the Marmara earthquake and the September 12 military coup. For other negative categories (e.g., the most shameful), there was practically no overlap with the most important $(1.67 \%)$ and greater variability in responses.

Therefore, we suggest that when people try to retrieve important public events, high-impact events that have been privately and publicly rehearsed and commemorated periodically immediately come to mind. We showed that there is a bump only for high-impact public events, suggesting that people who are young adults at the time of the event are more likely to report these events. The peak of the bump varied between the 3rd and 4th decade of life for the two bump events. Participant ratings of personal or generational importance, expectancy, and centrality to identity, however, did not show any age-at-event effect parallel to frequency of mention. One reason might be that participants were asked to report the most important event, leading to a restricted range for importance and self-related measures. There could also be other variables, such as rehearsal and media exposure, that might differ as a function of age at event. We did not collect rehearsal data for each event separately, so it remains as an empirical question, but there is some data showing that public event memories cued by cue words lead to differences in rehearsal for bump and nonbump memories but no difference in variables related to importance (Koppel \& Berntsen, 2016b).

Although we suggest, on the basis of our findings, that different processes might be at work in retrieval of public events compared to personal events, alternative accounts emphasizing common explanatory factors might be put forward. Indeed, the youth bias explanation (Koppel \& Berntsen, 2016a) represents one such account. Its potential strength comes from the fact that it is based on expectations, a factor that is central to the life-script explanation of the bump for personal events. The potential power of an expectation-based explanation of the bump for public events is difficult to deny, but substantial further data are needed to provide comparative tests of these accounts.

Another interesting observation in the present study was that participants had more difficulty coming up with positive public events (e.g., happiest, most proud) as evidenced by the number of participants who reported an event for these categories. As noted above, negative public events with significant loss of life are not uncommon in Turkey, and therefore actual frequency with which negative events occur and exposure to these news in the media might lead to this pattern. As suggested by Baumeister, Bratslavski, Finkenauer, and Vohs, (2001), "bad is stronger than good" (p. 323); bad events, bad emotions have more impact than good ones. Whether this difficulty to access happy events is a function of actual experiences of a nation remains an empirical question in need of cross-cultural studies including cultures that are politically more stable.

In conclusion, we provided further evidence that important and happiest personal memories show a bump corresponding to the 3rd decade of life and are best explained by the cultural life-script account. With regard to public events, we showed that a robust bump for public events occur only for high-impact events that are considered to be part of a nation's collective memory. Otherwise, retrieval of important public events and public events associated with different emotions are marked by recency. Thus, while the search of public memories are more likely to be chronologically retroactive in nature with the exception of high impact events, the retrieval of most important, happiest personal memories are driven by cultural schemas.

Author note The research reported here was financially supported by the Scientific and Technological Research Council of Turkey (TÜBİTAK) through Grant 111K396. A.B. was also supported by the Young Scientist Award Progam of the Science Academy (BAGEP). We would like to thank two anonymous reviewers for concrete and constructive comments. 


\section{Appendix 1}

\section{The questionnaire}

\section{Memory for Public Events}

In the last 70 years (1940s and onwards) there have been many events and changes in Turkey. Please specify the first event that comes to your mind when you think about the (...) public event in this period.

- Most Important

- Happiest

- Saddest

- Most Proud

- Most Shameful

- Most Hopeful

- Most Fearful

\section{Ratings for Public Events}

How important was the event for your self?

1- Very unimportant to 7- Very important How important was the event for your generation? 1- Very unimportant to 7- Very important How positive or negative was the event?

How expected was the event?

1- Very negative to 7- Very positive

This event is (...)

a part of my identity.

a reference point for my new experiences.

a turning point in my life.

\section{Memory for Personal Events}

What is your (...) personal memory.

- Most important

- Happiest

- Saddest

\section{Ratings for Personal Events}

How vivid was this memory?

How positive or negative was this event?

How expected was the event?

1- Very vague to 5- Very vivid

1- Very negative to 7- Very positive

1- Very unexpected to 5- Very expected

This memory is (...)

a part of my identity.

a reference point for my new experiences.

a turning point in my life.
1- Definitely no to 5- Definitely yes

1-Definitely no to 5- Definitely yes

1- Definitely no to 5- Definitely yes
1- Definitely no to 5- Definitely yes

1-Definitely no to 5- Definitely yes

1-Definitely no to 5- Definitely yes 


\section{Appendix 2}

Descriptions of the ten most frequently mentioned public events

\section{Event}

Sept. 12, military coup

Marmara earthquake

Van earthquake

Gezi protests

Peace process

Cyprus military operation

The coming to power of AKP

Madımak Hotel arson
May 27, military coup

\section{Description}

On September 12, 1980, the military overthrew the civilian government. More than 500 people were sentenced to death; 50 were executed; 650,000 people were under arrest.

On August 17, 1999, a devastating earthquake (magnitude 7.4) struck the industrial northwestern region of Turkey. 17,127 people died; 43,953 were injured; and more than 250,000 were displaced.

On October 23, 2011, a magnitude 7.2 earthquake occurred in Van, in the eastern part of Turkey. 604 people died, 4,152 were injured, and thousands of people were displaced.

On May 28, 2013, a civil unrest began in Istanbul, Turkey, initially to protest an urban development plan for Gezi Park, in Istanbul. Protests developed into wider antigovernment demonstrations.

This is the name given to a number of concrete developments aiming to resolve the Kurdish-Turkish conflict. The death toll of this conflict is estimated to be no less than 40,000 .

On May 27, 1960, the military overthrew the civilian government. Several members of the government were charged with various crimes. Prime minister Adnan Menderes was executed along with two other ministers.

In 1974, the Turkish military intervened in the island in response to a military coup taking place on the island. The operation resulted in a new border between northern and southern Cyprus.

The Justice and Development Party (Adalet ve Kalkınma Partisi; AKP), which is a conservative political party, came to power in Turkey in the general elections of 2002 and has won the general elections in 2002, 2007, 2011, 2015.

On July 2, 1993, a group of Islamic fundamentalists, gathered in front of the Madımak Hotel in the city of Sivas to protest a meeting of intellectuals, set the hotel on fire. Thirty-three intellectuals, two members of the hotel and two protesters were died.

Maraș events December 19-26, 1978, more than 100 people were killed and hundreds more were wounded.

\section{References}

Baumeister, R. F., Bratslavsk, E., Finkenauer, C., \& Vohs, K. D. (2001). Bad is stronger than good. Review of General Psychology, 5, 323-370.

Berntsen, D., \& Rubin, D. C. (2002). Emotionally charged autobiographical memories across the lifespan: The recall of happy, sad, traumatic and involuntary memories. Psychology and Aging, 17, 636-652.

Berntsen, D., \& Rubin, D. C. (2004). Cultural life scripts structure recall from autobiographical memory. Memory \& Cognition, 32, 427-442.

Berntsen, D., \& Rubin, D. C. (2006). The Centrality of Event Scale: A measure of integrating a trauma into one's identity and its relation to post-traumatic 925 stress disorder symptoms. Behaviour Research and Therapy, 44, 219-231.

Bohn, A. (2010). Generational differences in cultural life scripts and life story memories of younger and older adults. Applied Cognitive Psychology, 24, 1324-1345.

Bohn, A., \& Berntsen, D. (2013). Cultural life scripts and the development of personal memories. The Wiley handbook on the development of children's memory (Vols. 1/2, 626-644). Hoboken, NJ: Wiley.

Brown, N. R., \& Lee, P. J. (2010). Public events and the organizaton of autobiographical memory: An overview of the living-in-history-project. Behavioral Sciences of Terrorism and Political Aggression, 2, 133-149.

Conway, M. A. (2005). Memory and the self. Journal of Memory and Language, 53, 594-628.

Conway, M. A., \& Haque, S. (1999). Overshadowing the reminiscence bump: Memories of a struggle for independence. Journal of Adult Development, 6, 35-44.
Conway, M. A., \& Holmes, A. (2004). Psychosocial stages and the accessibility of autobiographical memories across the life cycle. Journal of Personality, 72, 461-480.

Conway, M. A., Wang, Q., Hanyu, K., \& Haque, S. (2005). A cross-cultural investigation of autobiographical memory on the universality and cultural variation of the reminiscence bump. Journal of Cross-Cultural Psychology, 36, 739-749.

Demiray, B., Gülgöz, S., \& Bluck, S. (2009). Examining the life story account of the reminiscence bump: Why we remember more from young adulthood. Memory, 17, 708-723.

Erdoğan, A., Baran, B., Avlar, B., Tas, A. Ç., \& Tekcan, A. I. (2008). On the persistence of positive events in life scripts. Applied Cognitive Psychology, 22, 95-111.

Erikson, E. H. (1950). Growth and crises of the healthy personality. In M. J. E. Senn (Ed.), Symposium on the healthy personality (pp. 91146). Oxford, UK: Josiah Macy Jr. Foundation.

Eurostat. (2008). Eurostat regional year book. Luxembourg: Eurostat. Retrieved from http://ec.europa.eu/eurostat/documents/3217494/ 5692801/KS-HA-08-001-EN.PDF/e77da79e-a9ef-4225-ba2f20e2e33ecffd

Fitzgerald, J. M. (1988). Vivid memories and the reminiscence phenomenon: The role of a self narrative. Human Development, 31, 261-273.

Fitzgerald, J. M. (1996). The distribution of self-narrative memories in younger and older adults: Elaborating the self-narrative hypothesis. Aging, Neuropsychology, and Cognition, 3, 229-236.

Fromholt, P., \& Larsen, S. F. (1991). Autobiographical memory in normal aging and primary degenerative dementia (dementia of Alzheimer type). Journal of Gerontology, 46, 85-91. 
Fromholt, P., Mortensen, D., Torpdahl, P., Bender, L., Larsen, P., \& Rubin, D. (2003). Life-narrative and word-cued autobiographical memories in centenarians: Comparisons with 80-year-old control, depressed, and dementia groups. Memory, 11, 81-88.

Glück, J., \& Bluck, S. (2007). Looking back across the life span: A life story account of the reminiscence bump. Memory \& Cognition, 35, 1928-1939.

Habermas, T., \& Bluck, S. (2000). Getting a life: The emergence of the life story in adolescence. Psychological Bulletin, 126, 748-769.

Holmes, A., \& Conway, M. A. (1999). Generation identity and the reminiscence bump: Memory for public and private events. Journal of Adult Development, 6, 21-34.

Howes, J. L., \& Katz, A. N. (1992). Remote memory: Recalling autobiographical and public events from across the lifespan. Canadian Journal of Psychology/Revue Canadienne de Psychologie, 46, 92116.

Jansari, A., \& Parkin, A. J. (1996). Things that go bump in your life: Explaining the reminiscence bump in autobiographical memory. Psychology and Aging, 11, 85-91.

Janssen, S. M. J. (2015). Is there a cultural life script for public events? Applied Cognitive Psychology, 29, 61-68.

Janssen, S. M. J., Chessa, A. G., \& Murre, J. J. J. (2005). The reminiscence bump in autobiographical memory: Effects of age, gender, education, and culture. Memory, 13, 658-668.

Janssen, S. M. J., Chessa, A. G., \& Murre, J. M. J. (2007). Temporal distribution of favourite books, movies, and records: Differential encoding and re-sampling. Memory, 15, 755-767.

Janssen, S. M. J., Murre, J. M., \& Meeter, M. (2008). Reminiscence bump in memory for public events. European Journal of Cognitive Psychology, 20, 738-764.

Janssen, S. M. J., Rubin, D. C., \& Conway, M. A. (2012). The reminiscence bump in the temporal distribution of the best football players of all time: Pelé, Cruijff or Maradona? The Quarterly Journal of Experimental Psychology, 65, 165-178.

Koppel, J. (2013). The reminiscence bump for public events: A review of its prevalence and taxonomy of alternative age distributions. Applied Cognitive Psychology, 27, 12-32.

Koppel, J., \& Berntsen, D. (2014). Does everything happen when you are young? Introducing the youth bias. The Quarterly Journal of Experimental Psychology, 67, 417-423.

Koppel, J., \& Berntsen, D. (2015a). The peaks of life: The differential temporal locations of the reminiscence bump across disparate cueing methods. Journal of Applied Research in Memory and Cognition, 4, 66-80.

Koppel, J., \& Berntsen, D. (2015b). There may not be a cultural life script for public events, but there is a youth bias: Response to Janssen (2014). Applied Cognitive Psychology, 29, 69-70.

Koppel, J., \& Berntsen, D. (2016a). The breadth and mnemonic consequences of the youth bias. The Quarterly Journal of Experimental Psychology, 69, 1265-1277.

Koppel, J., \& Berntsen, D. (2016b). The reminiscence bump in autobiographical memory and for public events: A comparison across different cueing methods. Memory, 24, 44-62.

Koppel, J., \& Rubin, D. C. (2016). Recent advances in understanding the reminiscence bump: The importance of cues in guiding recall from autobiographical memory. Current Directions in Psychological Science, 25, 135-140.

Ottsen, C. L., \& Berntsen, D. (2014). The cultural life script of Qatar and across cultures: Effects of gender and religion. Memory, 22, 390-407.

Pillemer, D. B. (2001). Momentous events and the life story. Review of General Psychology, 5, 123-134.

Rathbone, C. J., Moulin, C. J. A., \& Conway, M. A. (2008). Self-centered memories: The reminiscence bump and the self. Memory \& Cognition, 36, 1403-1414.
Roediger, H. L., \& DeSoto, K. A. (2014). Forgetting the presidents. Science, 346(6213), 1106-1109.

Rubin, D. C., \& Bernsten, D. (2003). Life scripts help to maintain autobiographical memories of highly positive, but not highly negative, events. Memory and Cognition, 31, 1-14.

Rubin, D. C., Rahhal, T. A., \& Poon, L. W. (1998). Things learned in early adulthood are remembered best. Memory and Cognition, 26, 3-19.

Rubin, D. C., \& Schulkind, M. D. (1997). The distribution of autobiographical memories across the lifespan. Memory \& Cognition, 25, 859-866.

Rubin, D. C., Wetzler, S. E., \& Nebes, R. D. (1986). Autobiographical memory across the adult lifespan. In D. C. Rubin (Ed.), Autobiographical memory (pp. 202-221). Cambridge, UK: Cambridge University Press.

Schrauf, R. W., \& Rubin, D. C. (1998). Bilingual autobiographical memory in older adult immigrants: A test of cognitive explanations of the reminiscence bump and the linguistic encoding of memories. Journal of Memory and Language, 39, 437-457.

Schuman, H., Akiyama, H., \& Knauper, B. (1998). Collective memories of Germans and Japanese about the past half-century. Memory, 6, 427-454.

Schuman, H., \& Corning, A. D. (2000). Collective knowledge of public events: The Soviet era from the great purge to glasnost. American Journal of Sociology, 913-956.

Schuman, H., \& Corning, A. (2012). The critical period and generational memory: Evidence for national and world events. Public Opinion Quarterly, 76, 1-31.

Schuman, H., \& Corning, A. (2014). Collective memory and autobiographical memory: Similar but not the same. Memory Studies, 2, 146-160.

Schuman, H., \& Rodgers, W. L. (2004). Cohorts, chronology, and collective memories. Public Opinion Quarterly, 68, 217-254.

Schuman, H., \& Scott, J. (1989). Generations and collective memories. American Sociological Review, 54, 359-381.

Schuman, H., Vinitzky-Seroussi, V., \& Vinokur, A. D. (2003). Keeping the past alive: Memories of Israeli Jews at the turn of the millennium. Sociological Forum, 18, 103-136.

Sehulster, J. R. (1996). In my era: Evidence for the perception of a special period of the past. Memory, 4, 145-158.

Svob, C., Brown, N. R., Reddon, J. R., Uzer, T., \& Lee, P. J. (2014). The transitional impact scale: Assessing the material and psychological impact of life transitions. Behavior Research Methods, 46, 448-455.

Tekcan, A. İ., \& Tartar, E. E. (2008, July). The life script across cultures and its relation to the distribution of positive and negative memories across life. 19th International Congress of Psychology, Berlin, Germany.

Tekcan, A. İ., Kaya Kızılöz, B., \& Odaman, H. (2012). Stability of cultural life scripts. A comparison of adolescents, young adults, and older adults. Memory, 20, 836-847.

Thomsen, D. K., Pillemer, D. B., \& Ivcevic, Z. (2011). Life story chapters, specific memories and the reminiscence bump. Memory, 19, 267-279.

Turkish Statistical Institute. (2014). Address Based Population Registration System Results. Census 2014. Retrieved from http:// www.turkstat.gov.tr/PreTabloArama.do.

Wertsch, J. V. (2017). National memory and where to find it. In Handbook of culture \& memory: Frontiers in cultural psychology series. New York, NY: Oxford University Press.

Zaromb, F., Butler, A. C., Agarwal, P. K., \& Roediger, H. L., III. (2014). Collective memories of three wars in United States history in younger and older adults. Memory \& Cognition, 42, 383-399. 